\title{
Recherche sur l'archéologie de la côte occidentale de Guyane
}

\section{Stéphen Rostain et Aad H. Versteeg}

\section{(2) OpenEdition}

\section{Journals}

Édition électronique

URL : https://journals.openedition.org/jsa/3973

DOI : $10.4000 /$ jsa.3973

ISSN : 1957-7842

\section{Éditeur}

Société des américanistes

\section{Édition imprimée}

Date de publication : 1 janvier 2003

Pagination : 161-175

ISSN : 0037-9174

\section{Référence électronique}




\title{
NOTES DE RECHERCHE
}

\section{RECHERCHE SUR L'ARCHÉOLOGIE \\ DE LA CÔTE OCCIDENTALE DE GUYANE}

\author{
Stéphen ROSTAIN * et Aad H. VERSTEEG **
}

\section{INTRODUCTION}

L'archéologie de la côte occidentale de Guyane demeure mal connue en dépit des quelques fouilles réalisées ces dernières années. En effet, il manque encore un travail d'analyse et d'interprétation des résultats. Une action collective de recherche (ACR) a donc été mise en place. Une ACR est un projet scientifique financé par le ministère de la Culture et de la communication, le ministère délégué à la recherche et aux nouvelles technologies, le CNRS et l'INRAP. L'un de ses principaux objectifs est de rassembler les données éparses et d'en collecter de nouvelles autour d'un thème afin de les étudier sous un jour nouveau et d'en publier les résultats sous la forme d'une synthèse.

L'ACR sur la préhistoire de la côte occidentale de Guyane a été acceptée par le ministère de la Culture à la fin de l'année 2002 et se déroulera sur trois ans. Une collaboration entre divers services et institutions a été mise en place, rassemblant autour d'un axe commun le CNRS, les services régionaux de l'Archéologie, l'INRAP, les universités de Paris I, de Paris X et de Leide (Pays-Bas). On s'est également assuré la coopération d'autres partenaires comme l'IRD, le BRGM ou des musées. Ce projet s'achèvera par la publication commune d'une monographie présentant les résultats obtenus.

La problématique de ce projet est d'intégrer les données archéologiques disponibles dans le cadre culturel des Guyanes. En effet, si quelques fouilles ont été réalisées ces dernières années en Guyane française et si du matériel a été collecté au Surinam, ces données n'ont pas été rattachées aux complexes culturels

* Archéologie des Amériques CNRS-UMR 8096 [rostain@mae.u-paris10.fr].

** Stichting Surinaams Museum, Fort Zeelandia, Paramaribo, Surinam [vrstg@wxs.nl].

Journal de la Société des Américanistes, 2003, 89-1 : p. 161 à 175. Copyright (C) Société des Américanistes. 
reconnus dans la région des Guyanes (Boomert 1980, 1983, 1993 ; Cruxent and Rouse 1958-1959 ; Evans and Meggers 1960 ; Meggers and Evans 1957 ; Rostain 1994a, b, c ; Versteeg 1985 ; Versteeg and Bubberman 1992).

\section{LES BASES DE L'ARCHÉOLOGIE DANS LES GUYANES}

On peut considérer que l'archéologie scientifique débute dans les Guyanes après la Seconde Guerre mondiale. Ses pionniers ont pour noms E. Abonnenc, D. C. Geijskes, B. J. Meggers et C. Evans, C. Osgood, H. et P. Reichlen, J. M. Cruxent et I. Rouse. Meggers et Evans ont produit deux volumes essentiels pour l'archéologie des Guyanes : dans le premier (1957), ils définissent les cultures préhistoriques d'Amapá et de l'île de Marajó ; dans le second (1960), ils reconnaissent celles du Guyana. À la même époque, Cruxent et Rouse (1958-1959) déterminent les principales traditions culturelles du Venezuela et, plus particulièrement, du bassin de l'Orénoque. Cinquante ans après, ces ouvrages demeurent des références pour l'étude archéologique des Guyanes. Ainsi, les cultures Mazagão et Aristé d'Amapá ont des prolongements à l'est de la Guyane française. De même, des cultures de traditions Saladoïde, Barrancoïde et Arauquinoïde de l'Orénoque sont reconnues au Surinam et en partie jusqu'à l'île de Cayenne.

À partir des années 1970, une nouvelle génération d'archéologues professionnels arrive dans les Guyanes. On doit à la plupart d'entre eux d'avoir approfondi la compréhension des traditions et des complexes culturels définis par leurs prédécesseurs. Les plus notables contributions sont celles de Boomert, de Roosevelt, de Versteeg et de Rostain. Boomert (1976, 1980, 1983, 1993) décrit les manifestations des traditions Saladoïde et Arauquinoïde au Surinam à partir des collections existantes. Roosevelt $(1980,1997)$ fouilla quelques sites du moyen Orénoque, ce qui lui permit de préciser les traditions Saladoïde, Barrancoïde et Arauquinoïde. Versteeg (1985; Versteeg and Bubberman 1992) réalisa des fouilles sur de nouveaux sites Barrancoïdes et Arauquinoïdes du littoral du Surinam et les présenta dans un cadre régional plus vaste. À partir de plusieurs fouilles, Rostain (1991, 1994a et b) définit la culture hybride Thémire et intégra les cultures de la côte de Guyane française dans le panorama précolombien existant entre l'Amazone et l'Orénoque.

\section{UN ENVIRONNEMENT CÔTIER SPÉCIFIQUE}

Les Guyanes sont actuellement divisées entre cinq pays qui sont, d'est en ouest, le Brésil (région d'Amapá), la Guyane française, le Surinam, le Guyana et le Venezuela (rive droite du bas Orénoque). Toutefois, il n'est pas infondé de considérer les Guyanes comme une immense île reposant sur un plateau Précambrien, délimitée au sud par le fleuve Amazone, à l'ouest par le Rio Negro et le 
Canal de Casiquiare, au nord par l'Orénoque et à l'est par l'océan Atlantique (Lézy 2000). Cet ensemble est estimé à $1800000 \mathrm{~km}^{2}$ (Helman 1983). On y distingue deux environnements principaux, l'intérieur et le littoral, des milieux contrastés qui ont eu des influences spécifiques sur leur occupation ancienne.

Le littoral de Guyane fait partie de la grande plaine sédimentaire quaternaire qui s'étend sur environ $1600 \mathrm{~km}$ de long de l'Amazone à l'Orénoque (Figure 1). Assez large au Surinam (où elle atteint $90 \mathrm{~km}$ dans le district de Nickerie à l'ouest) et dans une partie du Guyana, la plaine côtière devient relativement étroite en Guyane, n'atteignant que $5 \mathrm{~km}$ à l'ouest de l'île de Cayenne et en moyenne $16 \mathrm{~km}$ à l'est de celle-ci. Partout ailleurs ses dimensions se réduisent et, parfois, des affleurements du socle touchent le rivage, dans la baie de l'Oyapock, l'île de Cayenne, près de Kourou et d'Organabo. En tout cas, tant en vue aérienne que depuis la mer, le paysage est celui de côtes basses et souvent marécageuses, bordées, du côté atlantique, par la mangrove et les pinotières et, du côté sud, par la partie septentrionale du socle. La bande côtière combine des environnements d'eau salée, d'eau saumâtre et d'eau douce, juxtaposant terres inondées et inondables ainsi que différents types de cordons sableux exondés et une relative diversité végétale.

On distingue la plaine côtière récente de la plaine côtière ancienne, cette dernière s'appuyant sur les terres hautes. La plaine côtière ancienne, située entre 5 et $15 \mathrm{~m}$ d'altitude, est plutôt un paysage de savanes (hautes, basses ou arborées), d'îlots de forêt et de forêts galeries. Son modelé accidenté est caractérisé par de larges cordons limono-sableux (barres prélittorales) qui s'élèvent sur un substratum d'argiles marines évoluées de la formation pléistocène Coswine. Les barres prélittorales présentent des différences (types de crête et de disposition notamment) issues de leurs évolutions morphologique et pédologique. Parfois, ces barres sont allongées et séparées par des vallons étroits et hydromorphes; dans d'autres cas, elles ne constituent qu'un assemblage diffus de formes disposées au milieu d'aires plates et de dépressions inondées. En tout état de cause une chose est certaine : par leurs dimensions et par leur emplacement au milieu des savanes inondables en saison humide, les barres ont toujours été des emplacements privilégiés pour l'habitat.

La plaine côtière récente basse et marécageuse est d'une altitude inférieure à $4 \mathrm{~m}$. Elle est bordée du côté maritime par une mangrove; située en général à quelques dizaines de centimètres au-dessous du niveau des plus hautes marées, elle est partiellement soumise à la submersion par l'onde de la marée. Les dépôts comprennent des sédiments fins argileux et limono-argileux d'origine essentiellement amazonienne, et des sables, de grossiers à moyens, qui constituent des cheniers (cordons sableux) disposés parallèlement au rivage et séparés les uns des autres par des marais. Le milieu de cette basse plaine est donc plutôt amphibie, formé par des terres inondables et des marais, dans lesquels s'élèvent discrètement des cheniers, et des buttes aux contours festonnés appelées îlots de dissection. 


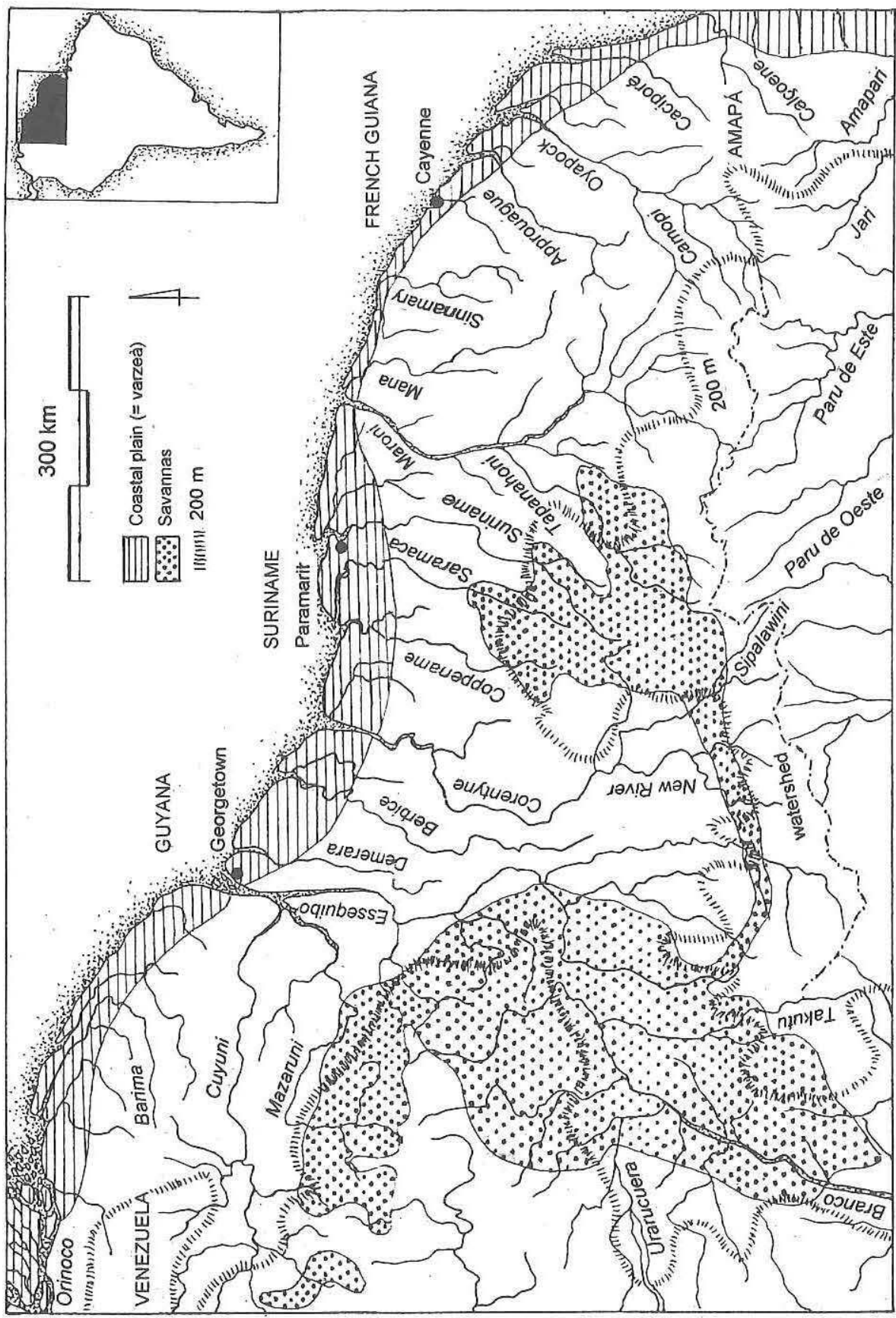


Cette formation s'emboîte directement dans la plaine côtière ancienne. Si cette jeune plaine côtière est peu importante en Guyane française, elle l'est en revanche nettement plus au Surinam et au Guyana où, par la richesse des sables coquilliers et des vases fertiles, elle fut densément occupée durant la préhistoire. On peut même affirmer que ce milieu connut les développements culturels précolombiens les plus importants.

La densité de vallons élémentaires et de petits cours d'eau (appelés localement " criques ») est assez forte. Ces émissaires ou bien débouchent dans les fleuves ou dans l'océan (fonctionnant alors comme des chenaux de marée), ou bien vont se perdre dans les marécages où, s'ajoutant aux précipitations, ils augmentent l'épaisseur de la couche d'eau qui stagne presque en permanence dans la basse plaine. Le profil d'équilibre des fleuves est extrêmement doux à l'approche de la bande côtière, où ils décrivent des nombreux méandres. L'effet de la marée se fait sentir assez haut sur les cours d'eau et atteint les premiers rapides des fleuves, par exemple à Petit Saut sur le Sinnamary. On constate que le cours inférieur de nombreuses rivières est nettement dévié vers le nord-ouest, ce qui s'explique par le transit sédimentaire côtier depuis l'embouchure de l'Amazone (les fleuves Sinnamary et Mana en Guyane française, Commewijne et Saramacca au Surinam sont d'excellents exemples). Certains de ces changements du rivage ont provoqué l'abandon de villages côtiers par les Amérindiens, comme à Grosse Roche sur l'Iracoubo. Le système de dispersion amazonien dans l'Atlantique équatorial modifie considérablement et très rapidement la morphologie du rivage, car environ 280 millions $\mathrm{m}^{3}$ de sédiments fins amazoniens circulent le long de la côte des Guyanes chaque année. Le rivage montre une alternance spatiale et temporelle de zones d'accrétion, occupées par de grands bancs de boue, et de zones d'érosion, se traduisant soit par la mangrove en recul, soit par des cheniers (Prost 1992). Ainsi, les transformations morphologiques de la ligne de rivage à très court terme rendent parfois précaire l'installation de villages côtiers.

\section{LA PRÉHISTOIRE DE LA CÔTE DES GUYANES}

Plusieurs cultures archéologiques ont été jusqu'à présent définies le long de la côte des Guyanes, de l'embouchure de l'Amazone au delta de l'Orénoque. L'île de Cayenne constitue une région charnière entre les influences culturelles du foyer Polychrome du bas Amazone et celles du foyer Arauquinoïde du moyen et du bas Orénoque (Rostain 1994c).

Dans l'aire qui nous intéresse, c'est-à-dire le littoral à l'ouest de l'île de Cayenne, les plus anciens sites reconnus sont attribués à la tradition Saladoïde. Ils sont localisés à la jonction de la plaine côtière et des hautes terres, au niveau des premiers rapides sur le fleuve Corantijn, à la frontière du Surinam et du Guyana. Ce sont Kaurikreek, daté d'environ 1000 ans av. J.-C., et Wonotobo Falls, daté du 
début de notre ère (Boomert 1983; Versteeg and Bubberman 1992). Hormis sur l'Orénoque, peu d'autres sites Saladoödes ont été reconnus et fouillés dans les Guyanes.

Les données stratigraphiques et chronologiques $\left({ }^{14} \mathrm{C}\right)$ des tourbières ainsi que les analyses polliniques montrent que des marais d'eau douce existaient sur le littoral occidental du Surinam de 300 à 1000 apr. J.-C. environ. Un groupe d'Amérindiens réagit et profita de cette situation en édifiant des monticules d'argile afin d'y établir leurs villages et en construisant dans les environs des champs surélevés contrôlés par des drainages déterminant ainsi un système élaboré d'agriculture permanente. Il était ainsi possible de fertiliser les champs artificiels avec les riches matières organiques des marécages tout en restaurant périodiquement le taux de fertilité désiré (Boomert 1976 ; Rostain 1991). En fait, ces populations ont recréé une várzea artificielle (terme appliqué aux parties des rives de l'Amazone et de l'Orénoque qui sont périodiquement inondées et reçoivent à cette occasion un dépôt d'argile jeune fertile autorisant une agriculture intensive).

Les premiers utilisateurs de ces techniques au Surinam étaient de culture Mabaruma, rattachée à la tradition Barrancoïde. Aux environs de 300 apr. J.-C., ils construisirent deux monticules voisins, Buckleburg-1 et -2, le long d'une petite rivière et entourés d'un réseau de champs surélevés quadrangulaires (Versteeg 1985). Les manifestations de cette culture sont limitées à l'extrême ouest du littoral du Surinam et une partie de la côte du Guyana.

À partir de 600 apr. J.-C., les groupes Barrancoïdes sont remplacés par des populations issues de la tradition Arauquinoïde. Celles-ci vont s'étendre progressivement d'ouest en est, depuis le Guyana oriental jusqu'à l'île de Cayenne. Si elles sont divisées en plusieurs cultures homogènes, elles appartiennent toutes à la même tradition Arauquinoöde et doivent être conçues comme un continuum géographique, chronologique et culturel. Les traits fréquemment associés aux cultures Arauquinö̈des des Guyanes sont des styles céramiques communs (Figure 2), l'installation des villages dans la plaine côtière et parfois sur des monticules artificiels, l'agriculture en champs surélevés associés à des systèmes élaborés de drainage (Figure 3). Bien que déjà reconnues dans la culture Mabaruma précédente, ces deux dernières caractéristiques sont bien plus fréquentes et perfectionnées dans la tradition Arauquinoïde. Quatre cultures Arauquinoïdes ont été identifiées le long de la côte des Guyanes (Figure 4) : Hertenrits, Kwatta, Barbakoeba et Thémire (Rostain and Versteeg 2003a et b).

La culture Arauquinoïde la plus ancienne est celle d'Hertenrits. Le monticule d'Hertenrits, le plus grand, est une élévation plus ou moins arrondie de 200-320 m de diamètre et de $2,5 \mathrm{~m}$ de hauteur au-dessus des marais environnants. Le monticule est entouré par un fossé de 20 à $100 \mathrm{~m}$ de largeur. Des chemins et/ou canaux régulièrement inondés partent radialement depuis l'élévation vers des ensembles de champs surélevés (Boomert 1980). Le territoire de la culture Her- 

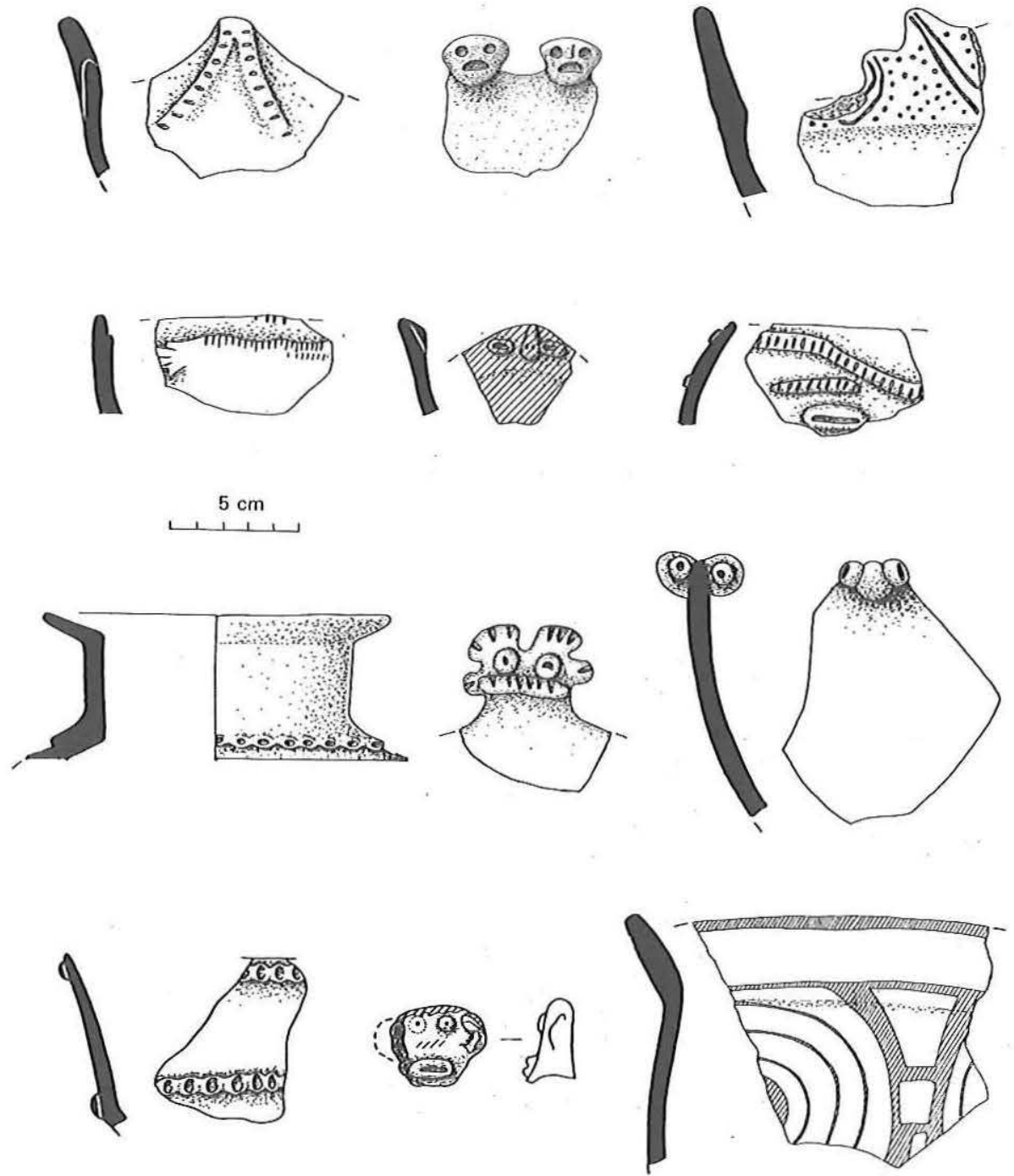

FIG. 2. - Quelques décors céramiques des quatre cultures Arauquinoïdes des Guyanes. Rang supérieur $=$ culture Hertenrits. Second rang = culture Kwatta. Troisième rang = culture Barbakoeba . Quatrième rang = culture Thémire (les hachures indiquent les zones peintes en rouge) 


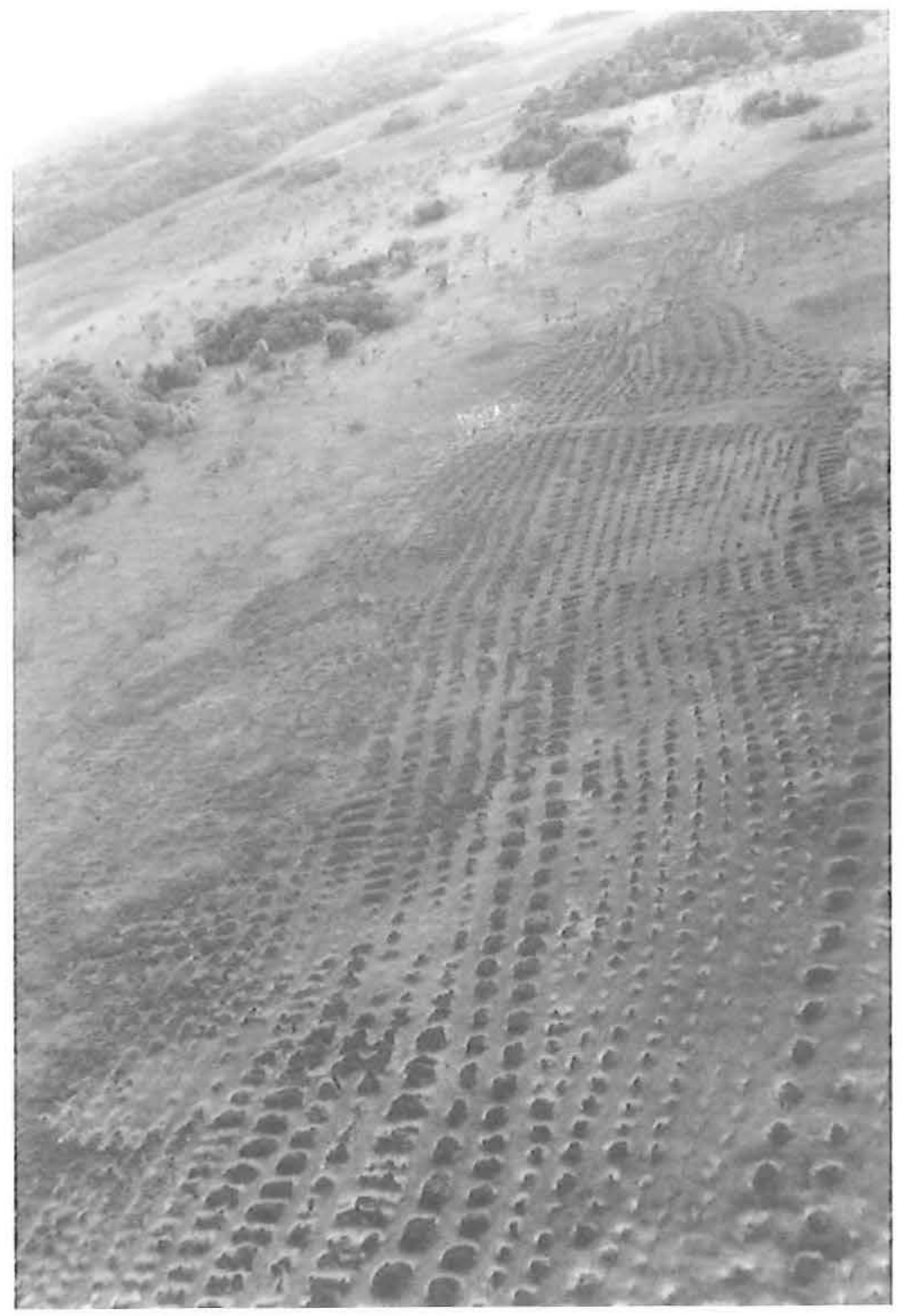

FIG. 3. - Champs surélevés à l'ouest de Kourou en Guyane française 


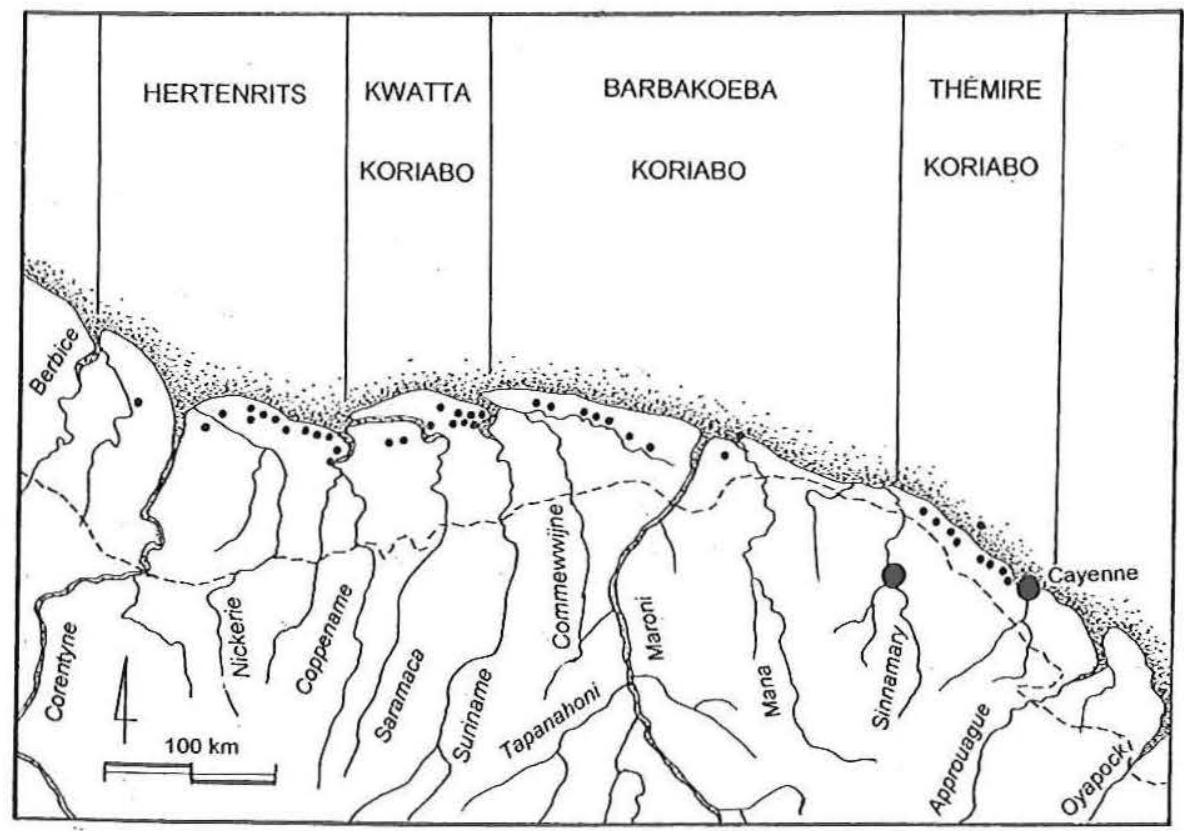

FIG. 4. - Carte des cultures de tradition Arauquinoïde du littoral des Guyanes. Avec ses exceptionnels monticules artificiels d'habitat, la culture Hertenrits de l'Ouest du Surinam représente la plus ancienne manifestation Arauquinoïde datée à partir de 600 apr. J.-C. Localisée sur la côte centrale du Surinam, la culture Kwatta fut probablement spécialisée dans la fabrication et le commerce d'objets particuliers. Principalement orientés vers l'agriculture, les groupes Barbakoeba cultivèrent une large aire entre la rivière Suriname et le fleuve Kourou. La culture Thémire représente l'extension la plus orientale de la tradition Arauquinoïde, mais elle montre quelque influence de la tradition Polychrome du bas Amazone

tenrits comprend à ce jour treize sites qui s'étendent entre les fleuves Berbice et Coppename, soit une frange côtière de $210 \mathrm{~km}$ de long et $25 \mathrm{~km}$ de large. Les défunts étaient enterrés dans les monticules d'habitat. Dans le site d'Hertenrits, les sépultures sont directes et primaires, secondaires en urnes ou mixtes (primaires et secondaires), et parfois accompagnées de poteries d'offrande. Il semble que certains sites étaient spécialisés pour des activités cérémonielles. Par exemple, Prins Bernhard Polder est exceptionnel par l'énorme quantité d'artefacts très élaborés de céramique, de pierre et de coquillage qui y fut découverte. Ils ont été trouvés dans de petites buttes de terre artificielles, sans équivalent dans les autres sites des Guyanes.

La culture Kwatta occupait le territoire juste à l'est de la précédente, entre les fleuves Coppename et Suriname, soit un espace de $92 \mathrm{~km}$ de long et $30 \mathrm{~km}$ de 
large. C'est l'unique culture Arauquinoïde des Guyanes qui ne soit pas associée à des champs surélevés. On peut supposer que la richesse en coquillages des sols des cheniers de cette aire fournissaient un terrain fertile autorisant une agriculture sur brûlis, suffisante pour nourrir les populations. Les villages Kwatta paraissent avoir joué un rôle prépondérant dans la manufacture d'artefacts et dans les échanges commerciaux. Ces groupes fabriquèrent en effet toute une panoplie d'ornements et d'outils en coquillage, en os ou en pierre. Ils fabriquaient notamment des pendentifs zoomorphes, essentiellement des batraciens, en pierre verte, plus communément connus sous le nom de muiraquitãs. L'autre centre amazonien de fabrication de ces muiraquitãs est localisé sur le moyen Amazone. Les artisans Kwatta échangeaient leurs productions avec leurs voisins, mais commerçaient également avec les populations de l'intérieur pour obtenir des produits rares sur la côte comme des préformes de hache qu'ils parachevaient eux-mêmes.

La culture Barbakoeba occupait un grand territoire allant du fleuve Cottica jusque probablement au fleuve Kourou, ce qui représente environ 200 par $25 \mathrm{~km}$. Peu de sites y sont pourtant pour l'instant connus et encore moins fouillés. L'aspect le plus remarquable de cette culture est l'agriculture sur champs surélevés. Ces derniers existent par milliers, ingénieusement disposés dans les marais en fonction des fluctuations du niveau des eaux (Rostain 1991). La culture Barbakoeba entretenait d'étroites relations avec les groupes Arauquinoïdes voisins, mais également avec la culture Koriabo totalement distincte des autres. Il semble que plusieurs sites de la région contiennent des céramiques Barbakoeba et Koriabo. Cette dernière culture, non rattachée à la tradition Arauquinoïde, s'est largement diffusée à travers toutes les Guyanes, principalement le long des fleuves principaux sans qu'on en connaisse précisément l'origine. Elle arrive vers 1100 apr. J.-C. sur le littoral, après les cultures Arauquinoïdes, et s'y maintient en certains endroits jusque peu après la conquête européenne.

La culture Thémire est localisée au centre du littoral de la Guyane française, à peu près entre le fleuve Kourou et l'île de Cayenne, c'est-à-dire sur environ $100 \mathrm{~km}$ de long pour $30 \mathrm{~km}$ de large. C'est la plus orientale des cultures Arauquinoïdes des Guyanes. Elle partage cependant quelques traits céramiques avec la culture voisine Aristé qui est issue du foyer de tradition Polychrome du bas Amazone. Comme chez les Kwatta, les sites Thémire de l'île de Cayenne ne sont pas associés à des champs surélevés, également en raison de la bonne fertilité des sols permettant ici encore l'agriculture sur brûlis. Les données de fouille suggèrent que certains villages Thémire se composaient de plusieurs grandes maisons, chacune d'entre elles avec son propre dépotoir, qui pouvaient entourer une place centrale (Rostain 1994a). Il faut noter que les cultures Barbakoeba et Thémire sont représentées dans des sites un peu plus intérieurs, notamment autour du premier saut du Sinnamary.

Les cultures Arauquinoïdes commencent à apparaître à l'ouest du Surinam à partir de 600 apr. J.-C., pour coloniser progressivement les terrains plus à l'est, 
jusqu'à l'île de Cayenne. À partir de 1250 apr. J.-C., la culture Hertenrits semble disparaître. Et de même qu'elles se sont installées peu à peu, les autres cultures s'éteignent les unes après les autres d'ouest en est. La culture Thémire est la dernière qui paraît survivre encore au moment de la conquête européenne.

\section{STRATÉGIE DU PROJET}

L'objectif principal du projet est de comprendre l'archéologie du littoral de Guyane grâce à une recherche exhaustive et une synthèse cohérente des données disponibles. À cette fin, une coopération a été mise en place entre chercheurs spécialisés sur les Guyanes, tant dans les sciences humaines que dans les sciences de la Terre. L'étude d'un large éventail d'informations permettra de dresser un bilan précis des connaissances.

Les fouilles programmées ont jusqu’à présent été peu nombreuses en Guyane française, la priorité ayant été donnée depuis une décennie à l'archéologie préventive. Si une grande quantité d'informations et de matériel a été récoltée, elle n'est en revanche que partiellement publiée. Les données primaires de fouilles sont généralement disponibles, mais les sites et les matériels ne sont pas intégrés dans un cadre englobant l'archéologie de toutes les Guyanes. Au Surinam et au Guyana, aucune fouille n'a été réalisée depuis près de quinze ans. En revanche, le musée de Fort Zelandia à Paramaribo (Surinam) et le Walter Roth Museum à Georgetown (Guyana) conservent des collections archéologiques anciennes partiellement décrites et qui ont rarement fait l'objet d'une publication. L'urgence est donc d'étudier les vestiges de ces trois pays afin de reconnaître ou de définir les cultures archéologiques représentées et de les replacer dans le contexte plus vaste des Guyanes. Le résultat de cette recherche permettra de mieux comprendre l'histoire, les modes de vie, les rites funéraires et les spécialisations des populations précolombiennes des Guyanes.

Par ailleurs, l'étude de la céramique des populations amérindiennes contemporaines du littoral des Guyanes (essentiellement les Kali'na, les Palikur et les Lokono) devrait aider à la connaissance des transformations culturelles et technologiques induites par la conquête européenne il y a plus de 500 ans. Archives et cartes anciennes seront également prises en compte.

Les collections existantes de Guyane française et du Surinam ont commencé à être analysées. La liste des sites fouillés à l'ouest de l'île de Cayenne a également été dressée. Les quatre cultures Arauquinoïdes sont inégalement connues. La plus occidentale, Hertenrits, a fait l'objet de plusieurs fouilles, tant dans les monticules que dans les autres sites, ce qui a fourni un abondant matériel archéologique. Celui-ci a amplement été publié (Boomert 1980 ; Versteeg 1985). Si de nouvelles fouilles ne semblent pas être actuellement prioritaires, elles seront néanmoins à envisager dans le futur. La culture Kwatta n'a pas encore été décrite, mais elle sera 


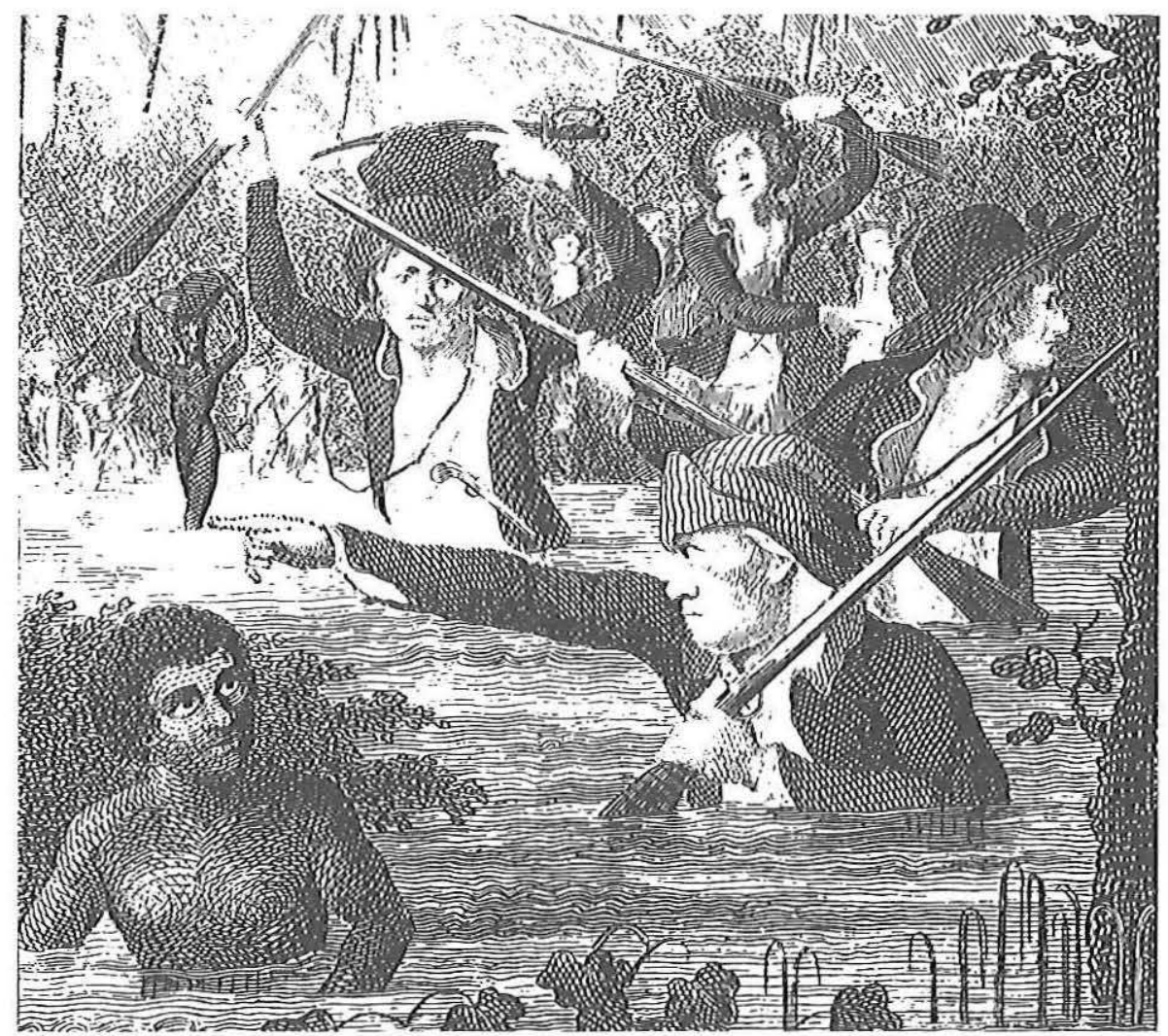

FIG. 5. - Les marais côtiers de l'Est du Surinam et de l'Ouest de la Guyane française furent peu prospectés par les Européens. Entre 1773 et 1777, un corps expéditionnaire hollandais y pourchassa des groupes d'esclaves fugitifs. Moins de $10 \%$ des 1200 militaires envoyés survécurent (voir illustration d'après Stedman 1800). Depuis cette époque, seuls quelques forestiers, comme F. Bubberman, ont visité cette région

présentée dans un manuscrit en cours de publication (Versteeg, sous presse). La culture Thémire, la plus récente et la plus orientale, a été analysée en détail par Rostain (1994a). Toutefois, si son implantation principale est l'île de Cayenne, les limites de ses prolongements occidentaux (entre Macouria et Kourou) ne sont pas encore clairement définies. Reste la culture Barbakoeba qui, bien que partiellement définie, demeure la plus méconnue (Boomert 1993 ; Rostain 1994b). Son aire d'implantation est la plus vaste (environ $200 \mathrm{~km}$ de long) mais, en dépit de son extension, moins d'une dizaine de sites ont été localisés et ils n'ont fait l'objet de pratiquement aucune fouille. Les milliers de champs surélevés repérés dans les 
marais littoraux de Guyane française et du Surinam correspondent à un nombre minimum de villages, plus ou moins grands, qui n'ont pas encore été trouvés. Ces villages Barbakoeba étaient installés sur des cheniers, au milieu de la plaine côtière, et sont aujourd'hui difficilement accessibles (Figure 5).

Afin de combler ce vide de la carte archéologique, des prospections seront organisées dans le territoire Barbakoeba et les photographies aériennes (des années 1999 et 2001) de l'Ouest de la Guyane française seront dépouillées pour repérer les champs surélevés et les sites. L'expérience des auteurs dans l'archéologie des Guyanes sera ici déterminante. La végétation couvrant les sites archéologiques diffère en effet très sensiblement de celle de la forêt primaire aux alentours ; cette distinction a été démontrée de manière très convaincante lors de l'étude de quatre monticules de cultures Barrancoïde et Arauquinoïde de l'Ouest du Surinam ; l'analyse botanique qui y fut menée a démontré d'ailleurs que $50 \%$ des espèces présentes sur ces sites sont utilisées ou utilisables par les populations amérindiennes actuelles de l'intérieur ; par comparaison, dans la forêt primaire, ce pourcentage tombe à $15 \%$ (Werkhoven and Versteeg 1980). La végétation semble refléter des activités amérindiennes. Il est probable que les espèces plantées sur les monticules durant leur occupation ont pu se propager et survivre jusqu'à nos jours. C'est la seule interprétation acceptable de la présence d'espèces utiles dans ces sites. De manière plus large, il est possible d'avancer que certains arbres et plantes poussant dans tout village étaient capables de se perpétuer durant plusieurs siècles après son abandon (Versteeg and Bubberman 1992). Ces faits seront très utiles durant les prospections le long des cheniers.

\section{CONCLUSION}

À partir du panorama des connaissances actuelles sur l'archéologie des Guyanes, on entraperçoit des vides importants dans plusieurs domaines. C'est le cas en particulier pour l'étude de certaines collections archéologiques et, plus préoccupant encore, pour celle de certaines cultures précolombiennes entières comme celle de Barbakoeba. Le projet ACR « Préhistoire de la côte occidentale de Guyane » se propose de combler ces lacunes par un travail de recherche mené en coopération et pluridisciplinaire. Grâce à une coopération entre institutions françaises (CNRS, SRA, INRAP, etc.) et internationales, notamment avec le Stiching Surinaams Museum à Paramaribo, on se propose de développer une recherche diachronique et culturelle sur l'ensemble du territoire guyanais de tradition Arauquinoïde avec, au premier chef, la culture Barbakoeba, qui couvre une partie de la Guyane française et du Surinam. 


\section{RÉFÉRENCES CITÉES}

BOOMERT A.

1976 "Pre-Columbian raised fields in Coastal Surinam ", Compte rendu du VI congrès international d'études des civilisations précolombiennes des Petites Antilles, Gainesville, pp. 134-144.

1980 "Hertenrits : an Arauquinoid complex in North West Surinam », Journal of the Walter Roth Museum of Archaeology and Anthropology, Georgetown, 3 (2), pp 68-104.

1983 "The Saladoid occupation of Wonotobo Falls, Western Suriname », Compte rendu du IX congrès international d'études des civilisations précolombiennes des Petites Antilles, Montréal, pp. 97-120.

1993 "The Barbakoeba archaeological complex of Northeast Suriname", OSO, Tijdschrift voor Surinaamse Taalkunde, Letterkunde, Cultuur en Geschiedenis, 12 (2), pp. 198-222.

Cruxent J. M. and I. Rouse

1958-1959 An archaeological chronology of Venezuela, Social Science Monographs 6, Washington, 2 vols.

Evans C. and B. J. MegGers

1960 Archeological investigations in British Guiana, Smithsonian Institution, Bureau of American Ethnology, bull. 177, Washington.

Helman A.

1983 De foltering van Eldorado: een ecologische geschiedenis van de vijf Guyana's, Nijgh \& Van Ditmar, Den Haag.

LÉZY E.

2000 Guyane, Guyanes. Une géographie "sauvage » de l'Orénoque à l'Amazone, Belin, Paris, coll. « Mappemonde ».

Meggers B. J. and C. Evans

1957 Archaeological investigations at the mouth of the Amazon, Smithsonian Institution, Bureau of American Ethnology, bull. 167, Washington.

Prost M.-T.

1992 «Sédimentation côtière et formation de cheniers en Guyane : la zone de Cayenne " in Évolution des littoraux de Guyane et de la zone caraibe méridionale pendant le Quaternaire, ORSTOM, Paris, pp. 397-414, coll. "Colloques et séminaires ».

Roosevelt A. C.

1980 Parmana. Prehistoric Maize and Manioc Subsistence along the Amazon and Orinoco, Academic Press, New York.

1997 The excavations at Corozal, Venezuela : stratigraphy and ceramic seriation, Yale University Publications in Anthropology, 83, New Haven. 
Rostain S.

1991 Les champs surélevés amérindiens de la Guyane, centre ORSTOM, Cayenne.

1994a L'occupation amérindienne ancienne du littoral de Guyane, ORSTOM éditions, Paris, 2 vol., coll. « Travaux et documents microfichés » 129.

1994b "The French Guiana coast : a key-area in prehistory between the Orinoco and Amazon Rivers », Between St. Eustatius and the Guianas, Publication of the St. Eustatius Historical Foundation, 3, St. Eustatius, pp. 53-97.

1994c "Archéologie du littoral de Guyane. Une région charnière entre les influences culturelles de l'Orénoque et de l'Amazone », Journal de la Société des Américanistes, 80, pp. 9-46.

Rostain S. and A. H. Versteeg

2003a "Territories and territoriality in the Guianas », in Oyuela-Caycedo and Chaumeil, eds, Territoriality, Territories and Boundaries on the last Frontier of Amazonia, (sous presse).

2003b " The Arauquinoid Tradition in the Guianas » in Delpuech and Hofman, eds, Late Ceramic Societies in the Eastern Caribbean, BAR, Monographs in American Archaeology, (sous presse).

STEDMAN J.-G.

$1800 \quad$ Voyage au Surinam et dans l'intérieur de la Guiane, contenant la relation de cinq années de courses et d'observations faites dans cette contrée intéressante et peu connue; avec des détails sur les Indiens de la Guiane et les Nègres; suivi du tableau de la colonie française de Cayenne. Traduit de l'anglais par P. F. Henry, 3 vol., in-8 et 1 atlas in-4, F. Buisson, Paris, An VII.

VACHER S., S. JÉrémie et J. BRIAND éds

1998 Amérindiens du Sinnamary (Guyane). Archéologie en forêt équatoriale, dAf 70 , éditions de la Maison des sciences de l'homme, Paris.

Versteeg A. H.

1985 " The Prehistory of the Young Coastal Plain of West Suriname », Berichten van de Rijksdienst voor het Oudheidkundig Bodemonderzoek, Jaargang 35, pp. 653-750.

2004 Suriname voor Columbus/Suriname before Columbus, Libri Musei Surinamensis 1, Paramaribo (sous presse).

Versteeg A. H. and F. C. Bubberman

1992 "Suriname before Columbus", Mededelingen Stichting Surinaams Museum, 49a, Paramaribo, pp. 3-65.

Werkhoven M. C. M. and A. H. Versteeg

1980 "The vegetation of four mounds in the coastal plain of Suriname ", Mededelingen Stichting Surinaams Museum, 32, Paramaribo, pp. 8-37. 